\title{
Impact of vegetation feedback on the temperature and its diurnal range over the Northern Hemisphere during summer in a $2 \times \mathrm{CO}_{2}$ climate
}

\author{
Su-Jong Jeong • Chang-Hoi Ho • Tae-Won Park • \\ Jinwon Kim · Samuel Levis
}

Received: 28 January 2010/Accepted: 12 April 2010/Published online: 4 May 2010

(C) The Author(s) 2010. This article is published with open access at Springerlink.com

\begin{abstract}
This study examines the potential impact of vegetation feedback on the changes in the diurnal temperature range (DTR) due to the doubling of atmospheric $\mathrm{CO}_{2}$ concentrations during summer over the Northern Hemisphere using a global climate model equipped with a dynamic vegetation model. Results show that $\mathrm{CO}_{2}$ doubling induces significant increases in the daily mean temperature and decreases in DTR regardless of the presence of the vegetation feedback effect. In the presence of vegetation feedback, increase in vegetation productivity related to warm and humid climate lead to (1) an increase in vegetation greenness in the mid-latitude and (2) a greening and the expansion of grasslands and boreal forests into the tundra region in the high latitudes. The greening via vegetation feedback induces contrasting effects on the temperature fields between the mid- and high-latitude regions. In the mid-latitudes, the greening further limits the increase in $T_{\max }$ more than $T_{\min }$, resulting in further decreases in DTR because the greening amplifies evapotranspiration and thus cools daytime temperature. The greening in high-latitudes, however, it reinforces the warming by increasing $T_{\max }$ more than $T_{\min }$ to result in a further increase in DTR from the values obtained without vegetation feedback. This
\end{abstract}

\footnotetext{
S.-J. Jeong · C.-H. Ho (ه) · T.-W. Park

Climate Physics Laboratory, School of Earth and Environmental

Sciences, Seoul National University, Seoul 151-742, Korea

e-mail: hoch@cpl.snu.ac.kr

J. Kim

Department of Meteorology, University of California,

Los Angeles, CA, USA

S. Levis

National Center for Atmospheric Research, Boulder, CO, USA
}

effect on $T_{\max }$ and DTR in the high latitude is mainly attributed to the reduction in surface albedo and the subsequent increase in the absorbed insolation. Present study indicates that vegetation feedback can alter the response of the temperature field to increases in $\mathrm{CO}_{2}$ mainly by affecting the $T_{\max }$ and that its effect varies with the regional climate characteristics as a function of latitudes.

Keywords Vegetation-climate feedback . Dynamic global vegetation model (DGVM) . Climate change · Greening ·

Diurnal temperature range (DTR)

\section{Introduction}

Daily mean temperatures over the Northern Hemisphere land surface have increased drastically during the recent several decades, and the warming trend is likely to continue into the future due to the continued increase in the atmospheric concentrations of anthropogenic greenhouse gases (GHGs), especially $\mathrm{CO}_{2}$ (Solomon et al. 2007). While the increase in the daily mean temperature is regarded as one of the most definite indicators of global warming, changes in the daily temperature maximum $\left(T_{\max }\right)$ and minimum $\left(T_{\min }\right)$ provide more detailed information than the mean temperature $\left(T_{\text {mean }}\right)$ alone because changes in $T_{\text {mean }}$ are attributed to changes in either $T_{\max }$ or $T_{\min }$, or both. Historical records show that the increase in $T_{\min }$ is larger than that in $T_{\max }$ (Karl et al. 1993; Easterling et al. 1997) and that the asymmetric changes in them result in decrease in the diurnal temperature range (DTR). The decrease in DTR is also regarded as a fingerprint for identifying the anthropogenic causes of global warming (Stone and Weaver 2003). Thus, future climate projections 
must evaluate not only mean temperatures but also the daily temperature extremes $\left(T_{\max }\right.$ and $\left.T_{\min }\right)$ and DTR.

The future DTR changes projected by various climate models have been examined in the Intergovernmental Panel on Climate Change (IPCC) the Fourth Assessment Report (AR4) (Meehl et al. 2007). General consensus among these models is that higher GHG concentrations will result in a decrease in DTR; continuation of this trend was already found in historical records (Solomon et al. 2007). The changes in DTR result from complex feedbacks among GHG concentrations, radiative transfer, atmospheric and oceanic circulations, clouds, and precipitation. For example, DTR decreases have been attributed to enhanced nocturnal temperatures due to increased longwave forcing; the changes in shortwave radiation and cloud amounts are also attributed to the projected DTR decreases. For instance, increases in cloudiness lessen surface insolation to reduce $T_{\max }$ and DTR (Stone and Weaver 2003). Nevertheless, there still exist large uncertainties regarding the response of daily temperature field to the increase in GHGs because the response of DTR to global climate conditions induced by the increase in GHGs are also controlled by a number of additional climate factors, such as land-surface vegetation and moisture availability (Dai et al. 1999; Stone and Weaver 2003; Zhou et al. 2009).

Previous studies reported that land-atmosphere interactions are important in determining DTR in addition to the changes in radiation and clouds, especially in boreal summers (Zhou et al. 2007; Zhang et al. 2009). For example, with sufficient surface moisture availability, increases in radiative energy input will mostly increase evapotranspiration to limit the increase in sensible heat flux and surface temperatures. By contrast, the lack of surface moisture limits evaporation and ground heat flux (Kim et al. 2002); thus the increased radiative energy input is primarily balanced by the increase in sensible heat flux. Thus, surface temperature increases are larger over drier surfaces than wet ones for the same amount of radiative forcing. The changes in surface energy budget indicate attenuation of daytime temperature increases over wet surfaces. In addition, sufficient moisture from the land can lead to an increase in precipitation, which further reduces incident shortwave radiation and $T_{\max }$ (Fischer et al. 2007). Considering these land-surface processes, vegetation is one of the important factors that regulate moisture availability and temperatures (Bonan 2001; Bonan et al. 2003). However, the role of vegetation feedback in shaping DTR variations remains to be quantified.

Satellite-derived leaf area index and/or station-observed vegetation phenology data show earlier emergence and enhancement of vegetation activity over most Northern Hemisphere (e.g., Myneni et al. 1997; Ho et al. 2006;
Schwartz et al. 2006). Climatic consequences of the increase in vegetation activity have been investigated in previous studies (e.g., Bounoua et al. 2000; Cowling et al. 2009; Jeong et al. 2009a, b). Jeong et al. (2009a, b) reported that the increase in vegetation greenness has reduced spring warming via a cooling effect of vegetationevapotranspiration feedback over East Asia. This process mainly affects $T_{\max }$ with minimal impact on $T_{\min }$. As more leaves emerge and flourish, evapotranspiration increases given sufficient moisture. So, the vegetation-evapotranspiration feedback can result in asymmetric responses between $T_{\max }$ and $T_{\min }$, and alter DTR changes associated with future $\mathrm{CO}_{2}$ increases.

In this study, we examine the potential impact of vegetation feedback on the DTR changes associated with an increase in $\mathrm{CO}_{2}$ during boreal summer. The impact of $\mathrm{CO}_{2}$ doubling on climate is obtained from a century-long global model run with and without the coupling of a dynamic global vegetation model (DGVM) that is employed to represent the effect of vegetation feedback in the global climate system (Bounoua et al. 1999; Levis et al. 1999; 2000; Notaro et al. 2007; O'ishi and Abe-Ouchi 2009).

\section{Model and experiments}

\subsection{Model}

The global climate model (GCM) used in this study is the National Center for Atmospheric Research (NCAR) Community Atmospheric Model version 3 (CAM3) that incorporates the most recent dynamics scheme and parameterized physics. The model used in this study has been configures with spectral T42 (approximately $2.875^{\circ} \times 2.875^{\circ}$ ) horizontally and 26 hybrid-sigma levels in the vertical. Detailed information on the model is documented in Collins et al. $(2004 ; 2006)$ and will not be repeated here. Land-surface processes in CAM3 are calculated by the Community Land Model version 3 (CLM3; Oleson et al. 2004) that calculates the heat, moisture, and momentum fluxes between land surfaces and atmosphere as well as the thermal and hydrologic processes at the surface and the interior of near-surface soil layer (Bonan et al. 2002; Oleson et al. 2004; Dickinson et al. 2006). A comprehensive discussion on CLM and the surface flux calculations have been provided in Oleson et al. (2004).

Coupled with CAM3 at a T42 horizontal resolution, CLM3 is comprised of 3,799 grid points, each a collection of sub-grid elements of four primary land cover types: glacier, lake, wetland, and vegetation. The vegetated portion of the grid cell is represented by the fractional coverage of plant functional types (PFTs). The model uses seven primary PFTs: namely, needle-leaf evergreen or deciduous trees, 
broadleaf evergreen or deciduous tree, shrub, grass, and crop. These seven primary PFTs are further refined to tropical, temperate, and boreal deciduous or evergreen trees, $\mathrm{C} 3$ and $\mathrm{C} 4$ grasses, and evergreen and deciduous shrubs by bioclimatic rules (Oleson et al. 2004). In each PFT, leaf phenology in the CLM3 is prescribed, and the seasonal course of leaf area index (LAI) for each PFT is derived through interpolating the monthly PFT-specific LAI from National Oceanic and Atmospheric Administration (NOAA)-Advanced Very High-Resolution Radiometer (AVHRR) data as described by Bonan et al. (2002).

In addition, the dynamic global vegetation model (DGVM; Levis et al. 2004) that characterizes the spatial and temporal variations in PFTs and LAI, is also included in the CLM to allow the interaction between land-surface vegetation and atmospheric conditions. The CLM-DGVM is a modified version of the Lund-Potsdam-Jena DGVM (Sitch et al. 2003). It simulates the biogeographic distributions of potential vegetation PFTs as a response of environmental conditions in terms of temperature, growing degree days, and precipitation. These climatic variables determine the survival and establishment of PFTs; competition among PFTs for water and light under the prevailing soil and climatic conditions is governed by foliage cover, leaf area, height, and rooting profiles of PFTs (Levis et al. 2004). LAI in each PFT of the CLM-DGVM is simulated by an interactive phenology scheme, which is adopted from the Integrated Biosphere Simulator (IBIS; Foley et al. 1996). The interactive LAI phenology has been parameterized on the basis of either regional- or globalscale observational studies in order to simulate the seasonal trajectories of LAI (Foley et al. 1996). The simulated LAI and its climatic impacts using CAM3 coupled with CLMDGVM (hereafter CAM3-DGVM) (Levis and Bonan 2004) have been shown to reasonably agree with observations (Schwartz and Karl 1990). CAM3-DGVM also showed good performance in simulating the present-day terrestrial ecosystem distributions (Bonan and Levis 2006) and the influence of vegetation feedback on regional warming (Jeong et al. 2009b). Although some shortcomings (i.e. without including shrub and crop fractions) still exist in the current DGVM, this kind of potential vegetation model is the only and the best way for evaluating the interaction between vegetation and climate until now (Bonan et al. 2003; Levis et al. 2004; Notaro et al. 2007).

\subsection{Experiments}

Using the CAM3-DGVM model, three ensemble simulations have been performed; one under the present-day $\mathrm{CO}_{2}$ concentrations $\left(1 \times \mathrm{CO}_{2}=355 \mathrm{ppmv}\right)$ with specified vegetation coverage and two under $2 \times \mathrm{CO}_{2}(=710 \mathrm{ppmv})$ conditions, with and without dynamic vegetation feedback.
CAM3-DGVM was spun up for 500 years to obtain the potential vegetation under the present-day climate, a hypothetical vegetation state that would occur in the absence of human influences (e.g., urbanization, deforestation, and change to cultivated area) using the climatological-mean sea surface temperatures (SSTs) and sea ice distributions (SICs) from the Hadley Centre for 1950-2000 and the climatological-mean GHG concentration for the same period (i.e., $1 \times \mathrm{CO}_{2}$ ).

Starting from the bare ground, CAM3-DGVM vegetation achieved an equilibrium state with the simulated climate after 400 years. That is, it took about 400 years spin-up time to establish stable vegetation distribution. Using the stable vegetation state as the initial field, we have done additional 100 years simulation for producing present vegetation (e.g. VegOn_1×). The VegOn_1 $1 \times$ represents a climate under the present-day (e.g., $1 \times \mathrm{CO}_{2}=355 \mathrm{ppmv}$ ) condition in the presence of fully active DGVM with SSTs and SICs derived from the 1990 control run of Community Climate System Model version 3 (CCSM3; Collins et al. 2006). Here, one thing to note that the present CAM3DGVM model experiment does not include the ocean model. So, to include the variations in oceanic state by the effect of the $\mathrm{CO}_{2}$ increase, SSTs and SICs derived from the 1990 control run and the $2 \times \mathrm{CO}_{2}$ run of CCSM3 are prescribed in the present-day and the $2 \times \mathrm{CO}_{2}$ simulations, respectively. The SSTs and the SICs datasets are obtained from the Earth System Grid (http://www.earthsystemgrid.org). Thus, additional VegOn_1× simulations should be required for matching the treatment of SSTs and SICs. After 100 years running VegOn_1 $\times$ simulation, a climatological mean vegetation state (CMVS) is then calculated as the average vegetation state for the last 30 years of the VegOn_1 $1 \times$.

Using the CMVS as the initial field, we have performed three 100-year-long global ensemble simulations in order to investigate the impact of vegetation feedback on the climate change induced by doubling the present-day $\mathrm{CO}_{2}$ concentrations: (1) VegOff_ $1 \times$ represents a climate under the present-day (e.g., $1 \times \mathrm{CO}_{2}=355$ ppmv) $\mathrm{CO}_{2}$ concentration and with the prescribed vegetation from CMVS (distribution of PFTs and LAI), (2) VegOff_ $2 \times$ represents a climate under the $2 \times \mathrm{CO}_{2}$ condition in the absence of dynamic vegetation feedback, namely, with the same vegetation fields used in VegOff_1 $1 \times$, and (3) VegOn_2 $\times$ represents a climate under the $2 \times \mathrm{CO}_{2}$ condition in the presence of fully active DGVM.

The 100-year model run time may be enough to get stabilized results for an experiment, e.g., VegOn_2x. When we have carefully checked the last 30-year model results, all ensemble simulations reached the equilibrium state. So, the climatology during the last 30-year in each experiment is used for analysis in the present study. Each experiment consists of five ensemble members with 
slightly different atmospheric initial conditions randomly selected in the last 5 years of VegOn_1 $1 \times$ simulation. Intraensemble differences are found to be small. We have not adjusted the simulated land temperature and rainfall toward observations to remove model biases that might degrade the quality of the vegetation simulation. This allows us to assess the coupled vegetation-climate feedbacks and evaluate parameterizations for vegetation response to the simulated climatic conditions.

We separate the effect of elevated $\mathrm{CO}_{2}$ from the vegetation feedback) as follows: VegOff_2 $\times$ minus VegOff_ $1 \times$ indicates the effect of elevated $\mathrm{CO}_{2}$ only, defined as the radiative effect; VegOn_2x minus VegOff_1 $1 \times$ includes both the radiative and the vegetation effect; VegOn_ $2 \times$ minus VegOff_ $2 \times$ isolates the vegetation feedback only. The same modeling studies were used for other purposes (Betts et al. 1997; Cao et al. 2009).

\section{Results}

\subsection{Changes in vegetation greenness}

Vegetation greenness is generally expressed in terms of vegetation types (e.g., PFTs), their fractional coverage, and
LAI that is a measure of vegetation density (Levis et al. 2004). Figure 1 displays the mean summertime distributions of dominant PFTs under the present-day $\mathrm{CO}_{2}$ conditions and their future changes due to the doubling of $\mathrm{CO}_{2}$ concentration (i.e., VegOn_ $2 \times$ minus VegOff_ $1 \times$ ). For simplicity, the PFTs of the model are grouped into three major categories: grasses (C3, C3 arctic, and $\mathrm{C} 4$ grasses), deciduous trees (temperate broadleaf and tropical broadleaf deciduous trees), and evergreen trees (temperate broadleaf, tropical broadleaf, temperate needleleaf, and boreal needleleaf evergreen trees). In the present-day $\mathrm{CO}_{2}$ simulations (Fig. $1 \mathrm{a}-\mathrm{c}$ ), grass is the dominant vegetation type in most regions. The dominance of deciduous and evergreen trees is seen in extensive areas of the mid- and high-latitude regions (e.g., Canadian and northern Europe boreal forests). Compared to the grass PFTs, both tree species occur less extensively in the mid- $\left(30^{\circ} \mathrm{N}-\right.$ $\left.50^{\circ} \mathrm{N}\right)$ and high-latitude $\left(50^{\circ} \mathrm{N}-80^{\circ} \mathrm{N}\right)$ regions, perhaps because soils in the CAM-DGVM simulation are too dry to support the observed vegetation (Levis et al. 2004; Bonan and Levis 2006). Accepting that this model underestimates forest cover in favor of grass lands, the simulations reasonably capture major ecosystems in the Northern Hemisphere land surfaces reported in previous modeling and observational studies (e.g., Levis et al. 2004; Bonan and Levis 2006; Lawrence et al. 2007).
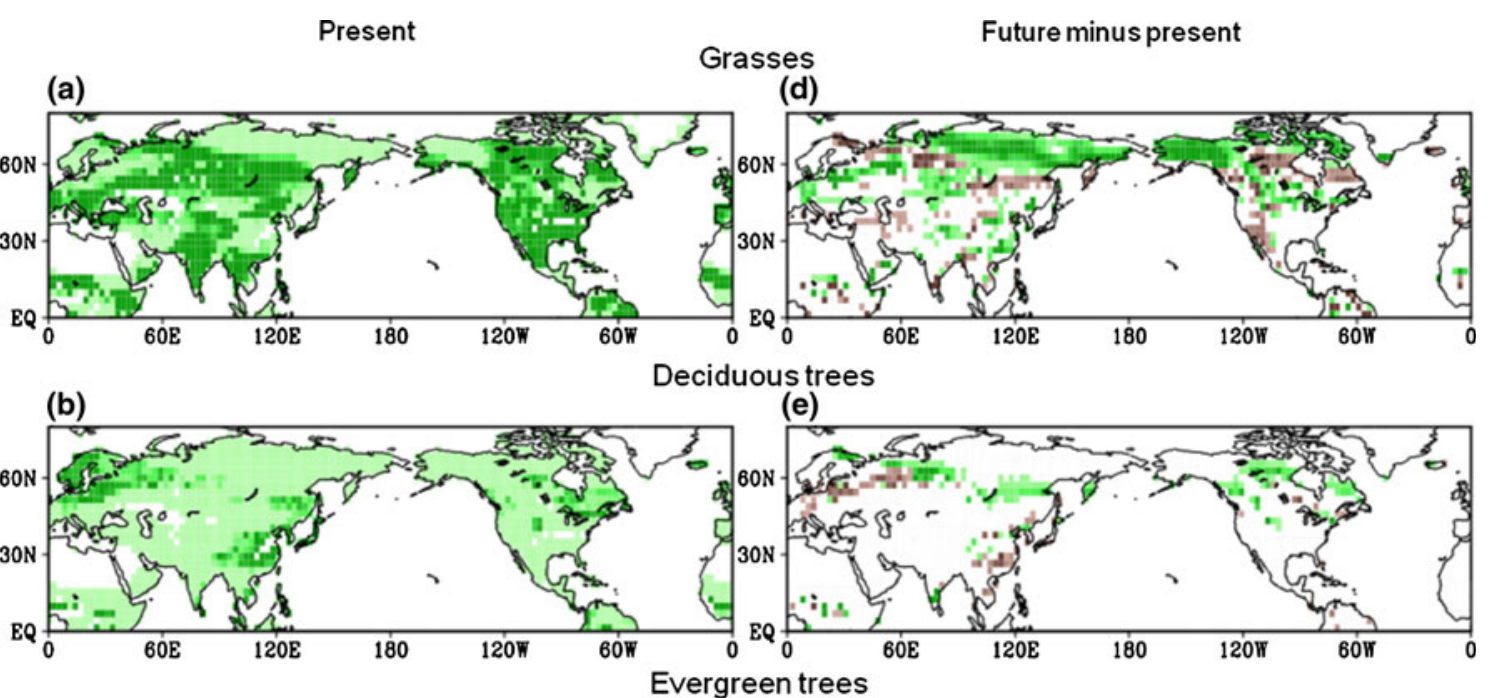

(c)

(f)

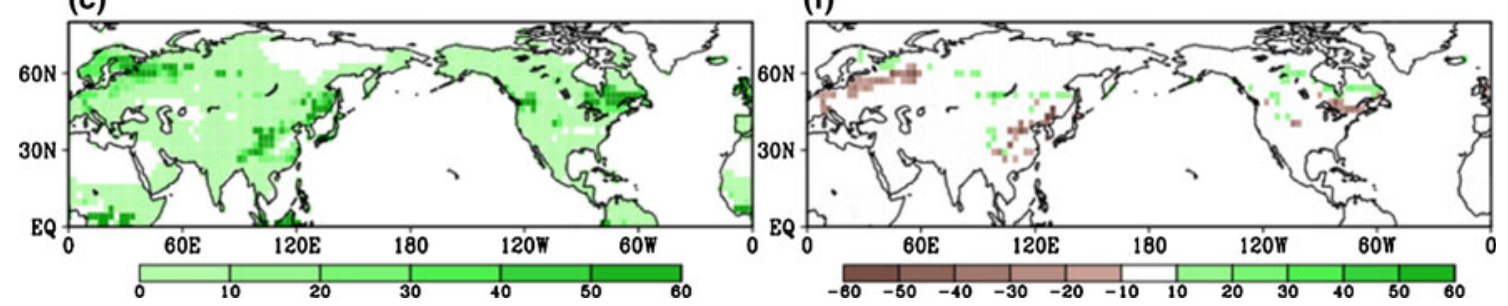

Fig. 1 Simulated mean plant functional types in VegOff_1 $\times$ experiments for grasses $(\mathbf{a})$, deciduous trees $(\mathbf{b})$, evergreen trees $(\mathbf{c})$, and changes

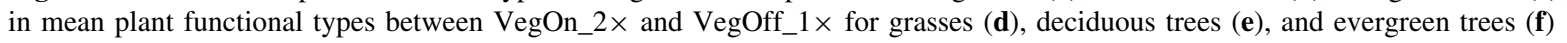


As the atmospheric $\mathrm{CO}_{2}$ concentration increases, all three vegetation types show changes (Fig. 1d-f). In VegOn_2x, the grass species increase clearly, especially in the high-latitudes. The northern limit of the grass land moves from $60^{\circ} \mathrm{N}$ to $80^{\circ} \mathrm{N}$ due to the doubling of $\mathrm{CO}_{2}$ concentration, implying that the sparsely vegetated surfaces in arctic permafrost and tundras in Alaska, Canada, and Eurasia are replaced with extensive grass lands. The tree-line species also moves northward. The poleward expansion of boreal forests is evident in northern Russia and Canada. Grass fractions decrease in regions where the trees increase. Most of the Northern Hemisphere region experiences an increase in vegetative fractions as shown in earlier studies (Levis et al. 2000; Notaro et al. 2007).

Consistent with the widespread enhancement in vegetative fractions, vegetation density as reflected in LAI is notably changed. Spatial distributions of LAI under the present-day $\mathrm{CO}_{2}$ concentration and its future changes (i.e., VegOn_2 $\times$ minus VegOff_1 $\times$ ) are shown in Fig. 2. Given the present-day $\mathrm{CO}_{2}$ condition, the largest LAI occurs in the tropics with the smallest LAI in the high-latitudes (Fig. 2a). Overall, the spatial distributions and magnitudes of LAI are consistent with satellite observations (Bonan et al. 2002; Lawrence et al. 2007). With increased atmospheric $\mathrm{CO}_{2}$ concentration, widespread increases in LAI are observed in VegOn_2x relative to that in VegOff_1 $1 \times$ (Fig. 2b). Greening denoted by the LAI increases in the warmer $2 \times \mathrm{CO}_{2}$ climate is mainly attributed to the increased vegetation productivity, water-use efficiency, as well as increases in vegetation fraction (Betts et al. 1997; Levis et al. 2000). Especially, the most notable LAI increases in the high-latitude region are closely related to the increase in vegetation fraction in sparsely vegetated

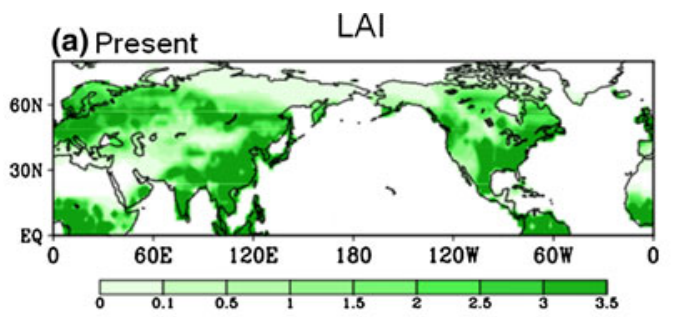

(b) Future minus present



Fig. 2 Simulated summer (June-August) leaf area index in VegOff_ $1 \times$ experiments (a), changes in leaf area index between VegOn_2x and VegOff_ $1 \times(\mathbf{b})$, the same as $(\mathbf{b})$ but for zonal mean distribution (c). The dotted mark in the figure indicates statistically significant at $95 \%$ confidence levels regions (e.g., tundra). These changes are similar to those found in previous studies (Betts et al. 1997; Levis et al. 2000). The LAI in south Asia, India, Iberian Peninsula, southwestern North America, and some parts of tropics decreases in the $2 \times \mathrm{CO}_{2}$ climate; however, these decreases in LAI are below the $95 \%$ confidence level in statistical significance tests based on Student's $t$ test. Thus, the vegetation feedback in this study generally results in increased vegetation greenness.

\subsection{Changes in temperatures: $T_{\text {mean }}, T_{\max }, T_{\min }$, and DTR}

Figure 3 shows the spatial distributions of the projected changes in $T_{\text {mean }}, T_{\max }, T_{\min }$, and DTR over the Northern Hemisphere in response to $\mathrm{CO}_{2}$ doubling due to the radiative effects only (Fig. 3a-d) and both the radiative effect and the vegetation feedback (Fig. $3 \mathrm{e}-\mathrm{h}$ ). The additional changes induced by the vegetation feedback (i.e., VegOn_2x minus VegOff_2x) are shown in Fig. 3i-1. In the absence of vegetation feedback, $T_{\text {mean }}$ generally increases in response to the increase in $\mathrm{CO}_{2}$ with the largest warming of $\geq 4^{\circ} \mathrm{K}$ in the high-latitude region (Fig. 3a). Its statistical significance exceeds $95 \%$ in most of the Northern Hemisphere. $T_{\max }$ and $T_{\min }$ also increase in most regions (Fig. 3b-c), except in central Africa where $T_{\max }$ decreases slightly. Differences in the increase of $T_{\max }$ and $T_{\text {min }}$ lead to regionally varying DTR changes (Fig. 3b-c).

Larger increases in $T_{\min }$ than $T_{\max }$ in the low- to midlatitude regions lead to uniform decreases in DTR. In other regions, however, the DTR changes show large regional variations (Fig. 3b-d). The most distinctive decrease in DTR is found in northern Africa, Arabian Peninsula, East Asia, and western North America. Over central Europe, northern Eurasia and eastern North America, DTR increases noticeably due to larger increases in $T_{\max }$ than $T_{\text {min }}$ (Fig. 3b-d). These changes in DTR are similar to the findings in Stone and Weaver (2003). Overall, the projected increases in $T_{\text {mean }}, T_{\max }, T_{\min }$, and DTR by the radiative effects of $\mathrm{CO}_{2}$ alone are similar to those reported in the IPCC AR4 (Meehl et al. 2007).

Greening in response to the $\mathrm{CO}_{2}$ increase causes welldefined additional warming by $1^{\circ} \mathrm{K}$ in $T_{\text {mean }}$ and $T_{\max }$ in the high-latitude regions of Eurasia and North America (Fig. 3i, j). Statistical significance of this additional warming in the region exceeds the $95 \%$ confidence level. The additional warming by $1^{\circ} \mathrm{K}$ in the high-latitude region (Fig. 3e) is comparable to the polar temperature amplification by vegetation feedback reported in Levis et al. (1999). In contrast, the changes in $T_{\min }$ by the radiative effects only are little affected by vegetation feedback in the same region (Fig. 3k). The greening reduces the warming induced by the radiative effect by $0.5^{\circ} \mathrm{K}$ in $T_{\text {mean }}$ and $T_{\text {max }}$ 


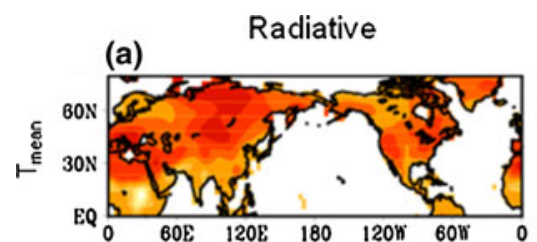

(b)

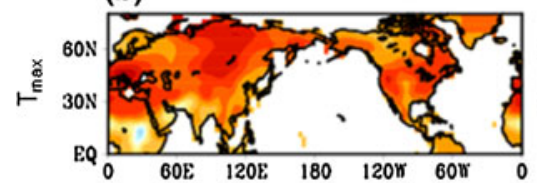

(c)

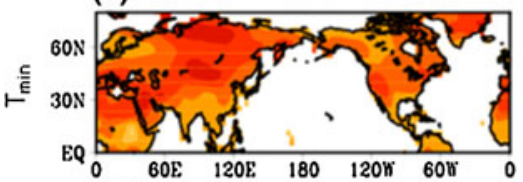

(d)



(e)

Radiative + Vegetation



(f)

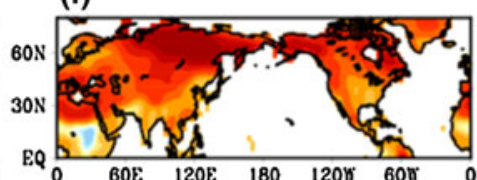

(g)

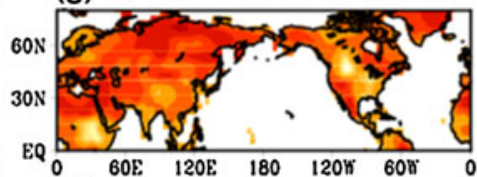

(h)

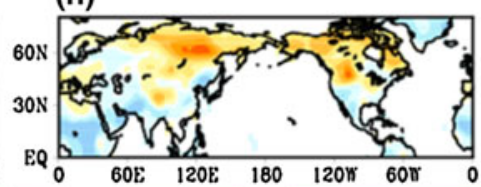

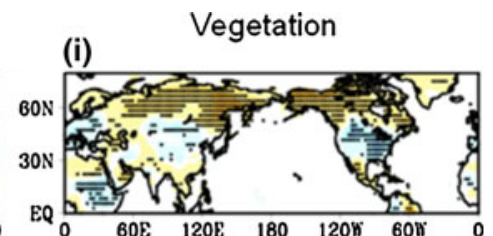

(j)

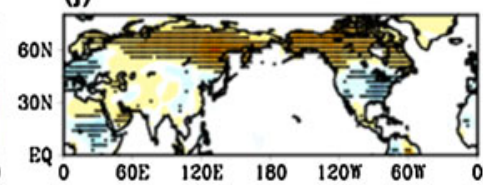

(k)

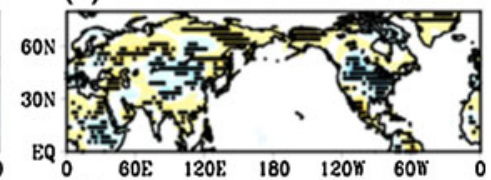

(I)

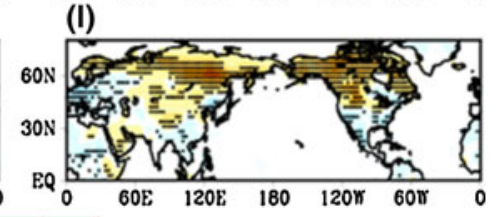

Fig. 3 Simulated changes in the daily mean $\left(T_{\text {mean }}\right)$, daily maximum $\left(T_{\max }\right)$, daily minimum $\left(T_{\min }\right)$ surface air temperatures and diurnal temperature range (DTR) during summer in Northern Hemisphere under the $2 \times \mathrm{CO}_{2}$ condition. The first column (a-d) represents the simulated changes by radiative effects only (i.e., fixed vegetation in

in the mid-latitude regions (Europe, East Asia, and southern and eastern North America) (Fig. $3 \mathrm{i}$ and $\mathrm{j}$, respectively). The cooling effects of the greening are at or above the $95 \%$ confidence level. Thus, the effects of vegetation feedback on the temperature changes by the increase in $\mathrm{CO}_{2}$ vary systematically according to latitude.

For a better understanding of the meridional variations in the effects of vegetation feedback on the temperature change, the zonal mean changes in $T_{\max }, T_{\min }$, and DTR are analyzed (Fig. 4). Solid squares in Fig. 4d-f indicate the projected changes are significant at the $95 \%$ confidence levels. The changes in $T_{\max }$ (Fig. 4a) show that the vegetation feedback limits and intensifies the increase in $T_{\max }$ in the mid-latitudes and the high-latitude regions, respectively. The results clearly show that while the increase in temperature lead to greening in the Northern Hemisphere, the effects of greening vary with latitudes: negative feedback in the mid-latitude and positive feedback in the highlatitudes. In contrast, in the effects of greening on the changes in $T_{\min }$ is small except in the mid-latitude regions where the increase in $T_{\min }$ is reduced slightly (Fig. $4 \mathrm{~b}$, e). Hence, the greening affects mostly the changes in $T_{\max }$ with minimal effects on $T_{\min }$. Consequently, the greening further decreases DTR in the mid-latitude region and increases DTR in the high-latitude regions (Fig. 4c, f). Unlike the previous studies that only examined the the present-day and $2 \times \mathrm{CO}_{2}$ climates). The middle column (e-h) shows the results for the radiative plus vegetation feedback effect. The third column (i-h) isolates the effects of the vegetation feedback. Dotted areas represent regions where temperature changes are statistically significant at the $95 \%$ confidence level

temperature changes by radiative effects (Stone and Weaver 2003; Zhou et al. 2009), this study shows that vegetation feedback affects DTR by limiting and enhancing $T_{\max }$ changes in the mid- and high-latitude regions, respectively.

\subsection{Changes in the surface energy budget}

The impact of vegetation feedback on the changes in the daily temperature field is mainly determined by a balance between the following two effects; an increase in LAI reduces albedo leading to further warming (i.e., positive feedback) but also enhances evapotranspiration to limit the warming (i.e., negative feedback) (Bonan 2008). Enhanced evapotranspiration may also intensify local precipitation and further strengthen the negative feedback (Cowling et al. 2009). The net effect of these competing processes determines the meridional variations in the temperature responses to vegetation feedback. In order to diagnose the climatic consequences of vegetation feedback in the midand high-latitude regions, the changes in the surface energy budget, including shortwave radiation (SW), longwave radiation (LW), sensible heat flux $(\mathrm{SH})$, and latent heat flux $(\mathrm{LH})$, are examined. The zonal mean values of all surface fluxes, precipitation, and albedo over land surfaces by the radiative and radiative plus vegetation feedback effects, 
(a)



(b)

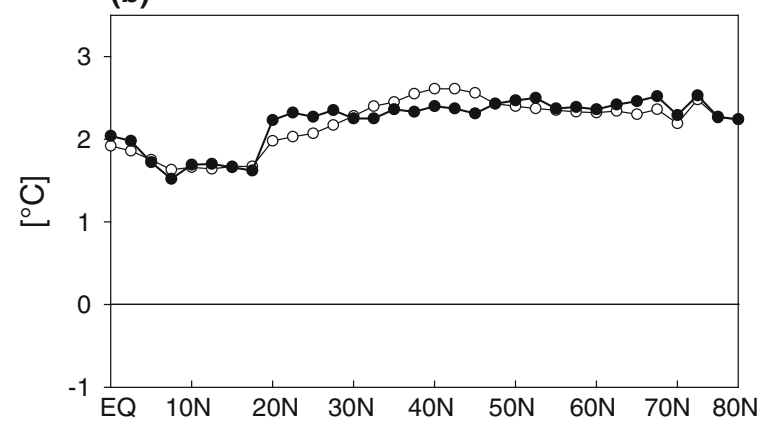

(c)



Fig. 4 Zonal mean distributions of simulated changes in $T_{\max }, T_{\min }$, and DTR during summer in Northern Hemisphere under the doubled $\mathrm{CO}_{2}$ condition. The left column (a-c) represents the simulated changes by radiative effects only (open circle) and radiative plus

and the isolated vegetation feedback effects alone are presented in Fig. 5. The results show that noticeable changes in the surface energy budget by vegetation feedback are only observed from mid- to high-latitude regions where vegetation changes have occurred (Fig. 5a-f). In addition, the changes in the surface energy fluxes by vegetation feedback are distinctly different between the midand high-latitude regions (Fig. 5g-1).

In the mid-latitudes, vegetation feedback reduces SW and increases LW from that by the radiative effect (Fig. $5 \mathrm{~g}$ ) because of the increase in cloudiness (Fig. 5k). The increase in LW is larger than the decrease in SW resulting in the increase in net radiation. This also shows
$T_{\max }$ (d)

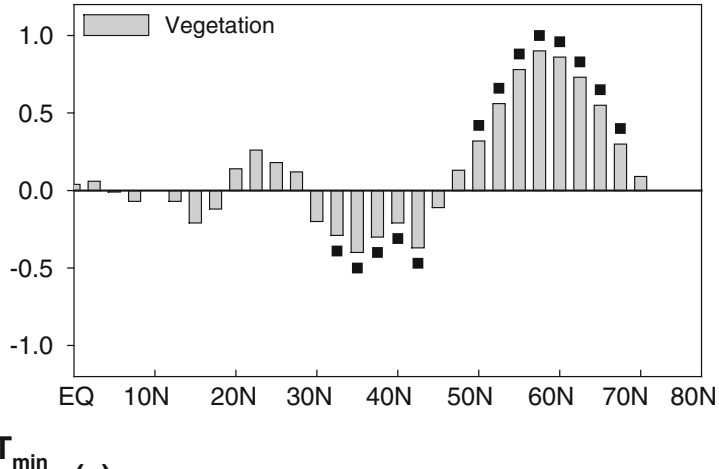

(e)



DTR

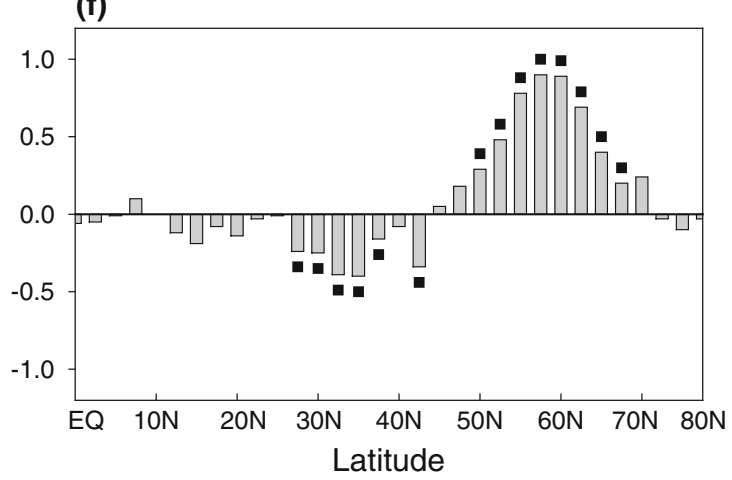

vegetation feedback effect (closed circle). The right column (d-f) represents the simulated changes by vegetation feedback effects only. Squared marks represent regions where temperature changes are statistically significant at the $95 \%$ confidence level

that enhanced transpiration by greening also increases precipitation in the region. This result is qualitatively consistent with the previous studies that reported positive relationship between greenness and precipitation (Betts et al. 1997; Cowling et al. 2009). The increase in the net radiation (SW plus LW) is compensated primarily by the increase in $\mathrm{LH}$; the results show that $\mathrm{SH}$ even decreases in this case (Fig. 5i-j). The surface energy partitioning shows that the greening limits the temperature increases via enhancing evapotranspiration and reducing insolation. Consequently, greening results in negative feedback and limits the increase in the near-surface temperature. 
(a)
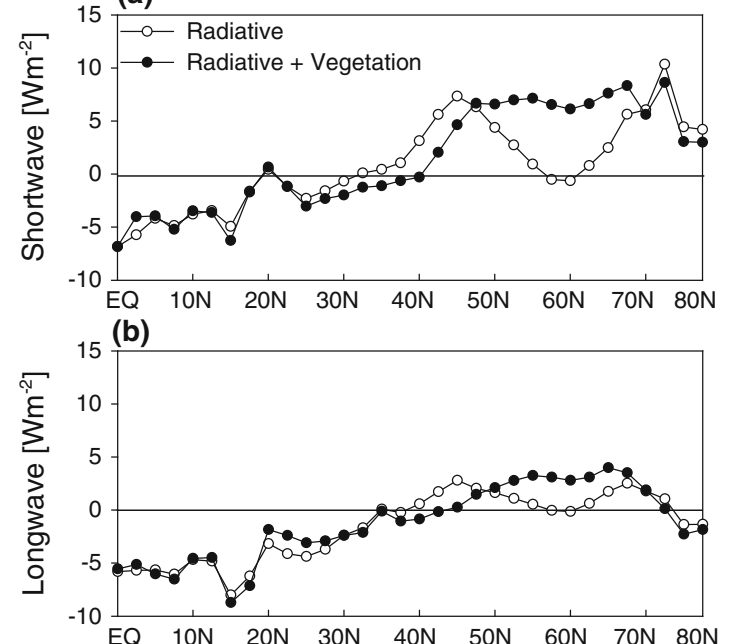

(c)
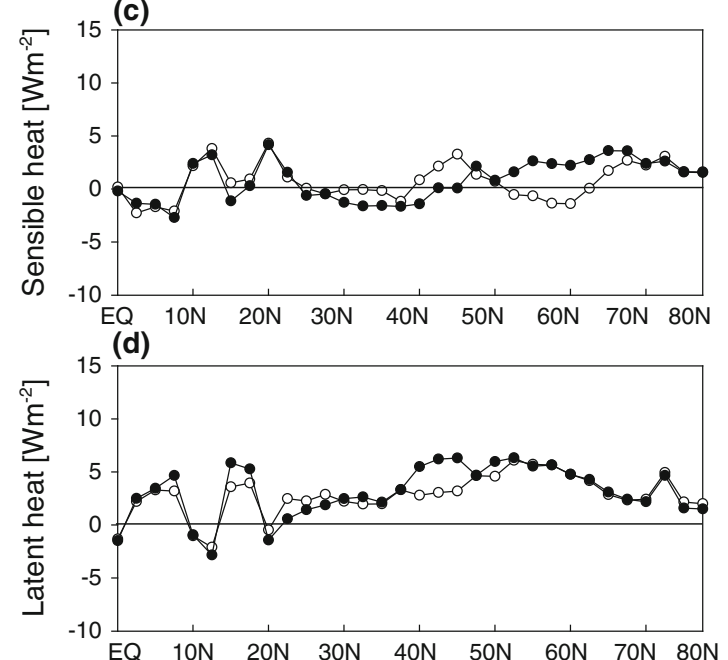

(e)

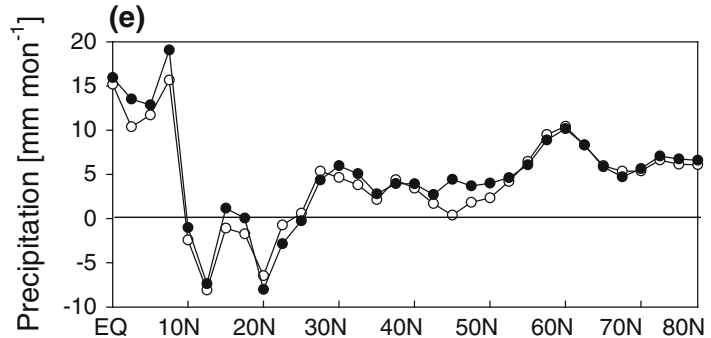

(f)

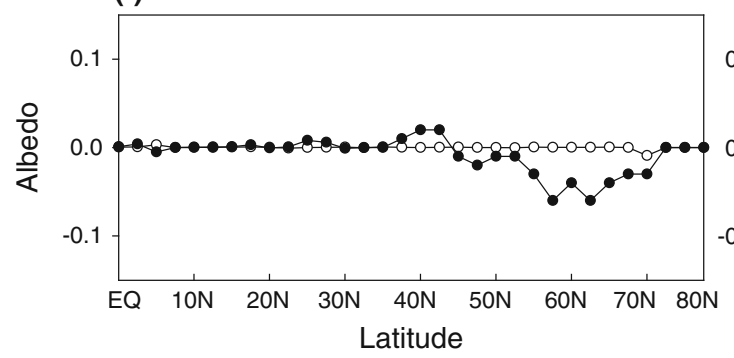

8 (g)
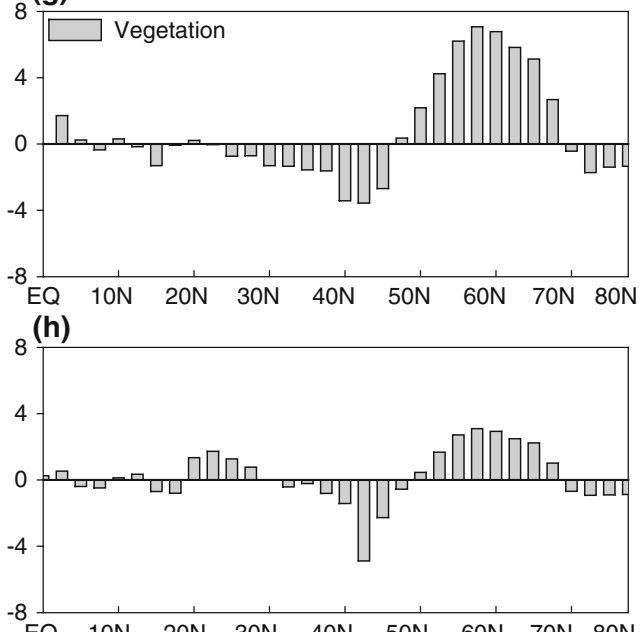

(i)


(k)

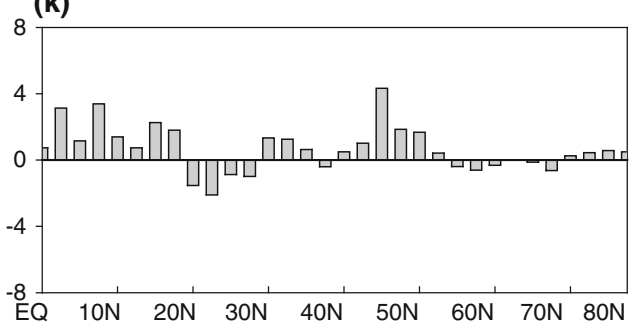

(I)

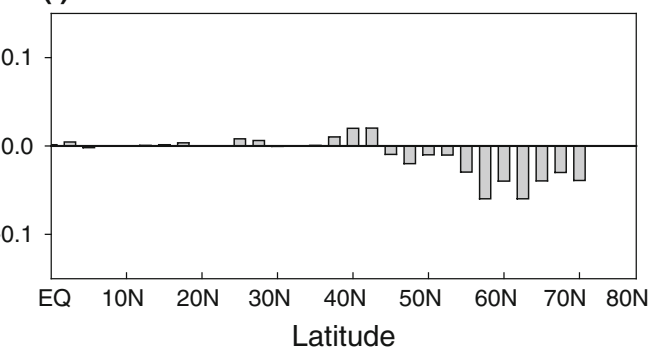

Fig. 5 Zonal mean distributions of simulated changes in the shortwave radiation (SW), longwave radiation (LW), sensible heat flux $(\mathrm{SH})$, latent heat flux $(\mathrm{LH})$, precipitation, and albedo during summer in Northern Hemisphere under the doubled $\mathrm{CO}_{2}$ condition. The left column (a-f) represents the simulated changes by radiative effects only (open circle) and radiative plus vegetation feedback effect (closed circle). The right column (g-l) represents the simulated changes by vegetation feedback effects only 
In the high-latitudes $\left(50^{\circ} \mathrm{N}-70^{\circ} \mathrm{N}\right)$, the most noticeable changes occur in SW (Fig. 5g). Enhanced greening significantly increases SW because the greening results in the decrease in surface albedo (Fig. 5l). As a result, the greening in the warmer $2 \times \mathrm{CO}_{2}$ climate intensifies the warming by increasing the $\mathrm{SW}$ absorption via surface albedo feedback, a positive one. In addition, most of the increase in net radiation is compensated by the increase in $\mathrm{SH}$ (Fig. $5 \mathrm{i}, \mathrm{j}$ ). This energy partitioning between $\mathrm{SH}$ and $\mathrm{LH}$ is consistent with the additional warming in the high latitude region. The dominant impact of greening on the low-level temperature changes in the high-latitude region is via surface albedo (Fig. 5l), not evapotranspiration. Thus, greening results in a positive feedback to enhance the radiative warming in the highlatitude region, which is similar to previous studies (Levis et al. 1999; Cowling et al. 2009).

Changes in the surface energy fluxes in the mid- and high-latitude regions (Fig. 5) show that vegetationevapotranspiration and vegetation-albedo feedback are the dominant factors in determining the effects of greening on temperature variations in the mid- and high-latitudes, respectively. Greenness increases more in the high-latitudes than in the mid-latitudes, but the magnitudes of changes in LH are negligible in the high-latitudes. This suggests that vegetation in the high latitude regions experience higher water stress in the $2 \times \mathrm{CO}_{2}$ climate. Changes in LH related to the vegetation feedback can be examined through the changes in total evapotranspiration, made up of transpiration, canopy evaporation, and soil evaporation (Oleson et al. 2004). The sum of vegetation transpiration and canopy evaporation has formed the basis of vegetation evapotranspiration.

Figure 6 shows the zonal mean changes in the total evapotranspiration, vegetation evapotranspiration, and soil evaporation in the Northern Hemisphere due to the $\mathrm{CO}_{2}$ doubling. The changes due to radiative plus vegetation effects and radiative-only effects are shown in Fig. 6a-c, and the vegetation feedback effects are presented in Fig. 6d-f. Dotted line in Fig. 6d-f represents changes in LAI, red color over the dotted line means statistically significant LAI increase at the $95 \%$ confidence level. Without vegetation feedback (i.e., radiative effect only), the total evapotranspiration increases everywhere in the mid- and high-latitude regions (Fig. 6a). Both vegetation evapotranspiration and soil evaporation increases in these regions. With greening, vegetation evapotranspiration increases where LAI increases (dotted lines in Fig. 6d-f), but soil evaporation decreases. Total evapotranspiration increases in the mid-latitudes and changes little in the highlatitudes due to different vegetation greening effects between the two regions. In mid-latitudes, most of vegetation greening is explained by LAI increases. Vegetation evapotranspiration directly transfers moisture from the soil interior to atmosphere with little impact on the surface soil (Kim and Ek 1995). Enhanced grass fractions in highlatitudes transfers soil moisture from shallow root layers in the upper soil to atmosphere. Thus, soil evaporation is reduced. This is consistent with previous greenness sensitivity study of evapotranspiration and soil moisture changes (Zhang and Walsh 2006).

\section{Discussion and conclusions}

\subsection{Discussion}

DTR is determined by the difference between the daytime $\left(T_{\max }\right)$ and nocturnal temperature extremes $\left(T_{\min }\right)$. The nighttime temperature is largely affected by downward longwave radiation. The daytime temperature is strongly affected by the surface solar heating and partitioning of SH and LH (Dai et al. 1999). Thus, the changes in DTR are determined through the changes in GHGs, clouds, aerosol, and land-surface properties. The IPCC AR4 models have traditionally focused on the changes in anthropogenic GHGs and their impacts on climate. These studies show that the increase in GHGs cause larger warming in $T_{\min }$ than $T_{\max }$, resulting in a substantial decrease in DTR over most Northern Hemisphere lands (Meehl et al. 2007). However, these studies do not include climate-vegetation feedbacks. The modeling study presented here shows that vegetation feedback may affect the changes in $T_{\max }$ and DTR over Northern Hemisphere land. Understating the role of vegetation feedback can help us understand the physical processes in the projected DTR changes in response to the increase in $\mathrm{CO}_{2}$.

Climate model simulations with and without vegetation feedback show that the vegetation-evapotranspiration and vegetation-albedo feedback are important factors in regulating daytime temperatures over land surfaces. Furthermore, the relative importance of these two feedback mechanisms varies according to latitude. A schematic diagram of the impact of greening on $\mathrm{CO}_{2}$-induced warming in the mid- to high-latitude regions (above $30^{\circ} \mathrm{N}$ ) is shown in Fig. 7. Positive signs indicate amplification factors in the increase in $T_{\max }$, whereas negative signs denote attenuation factors in the warming due to $\mathrm{CO}_{2}$. In the mid-latitudes, an increase in greenness by $0.8 \mathrm{~m}^{2} \mathrm{~m}^{-2}$ leads to an increase in evapotranspiration by $4 \mathrm{~mm}$ month $^{-1}$. That is accompanied by an increase in precipitation by about $3 \mathrm{~mm}$ month $^{-1}$. Enhanced evaporative cooling offsets the warming associated with the decrease in surface albedo that could have caused additional warming. Significant increases in LH reduce the daytime temperature maximum. Consequently, greening alleviates the warming caused by the $\mathrm{CO}_{2}$-induced radiative effect in the mid-latitude region. 
(a)



(b)

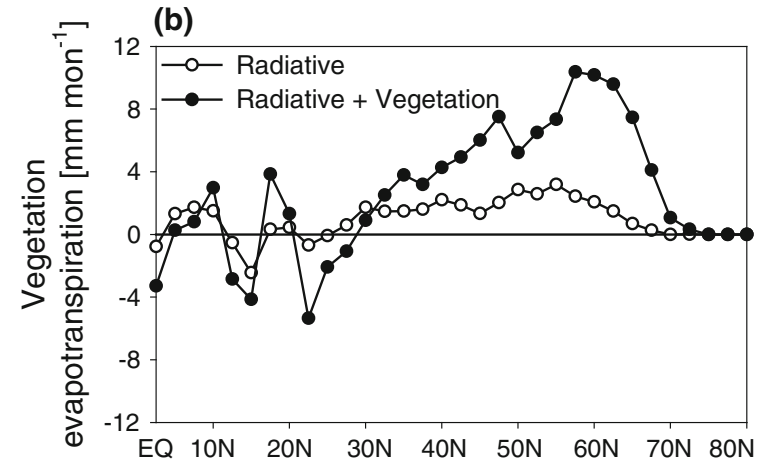

(c)

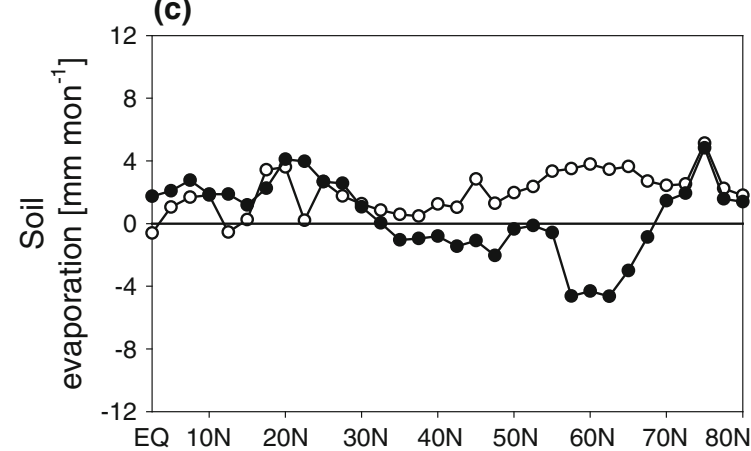

(d)

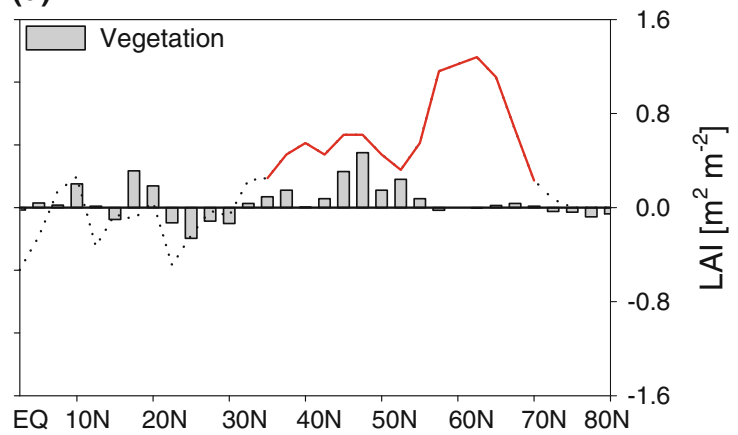

(e)

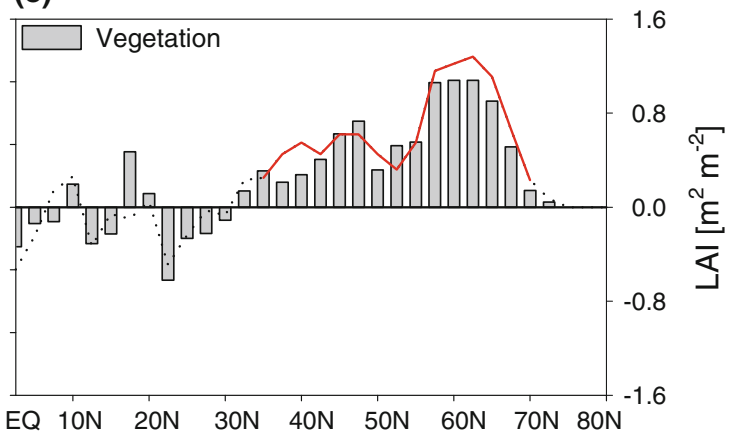

(f)

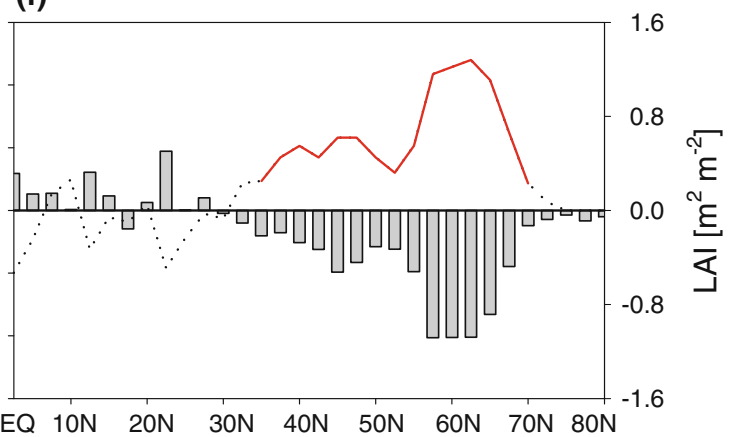

Fig. 6 Zonal mean distributions of simulated changes in the total evapotranspiration, vegetation evapotranspiration, and soil evaporation during summer in Northern Hemisphere under the doubled $\mathrm{CO}_{2}$ condition. The left column $(\mathbf{a}-\mathbf{c})$ represents the simulated changes by radiative effects only (open circle) and radiative plus vegetation

The impact of greening on $T_{\max }$ and DTR in the highlatitudes, however, is different from that in the mid-latitudes. Enhanced vegetation fraction accompanied by poleward shifts of boreal forests and the expansion of grass into the tundra region, lead to significant albedo decreases. The decreased albedo allows additional SW absorption by $5 \mathrm{~W} \mathrm{~m}^{-2}$ to result in additional temperature increases by $0.9^{\circ} \mathrm{K}$. The increase in greenness leads to an increase in transpiration offset by a decrease in soil evaporation. Further, a substantial fraction of the net radiation change is compensated by $\mathrm{SH}$ rather than $\mathrm{LH}$, which denotes warmer surface air over the region. Analyses of $T_{\max }$ and $T_{\min }$ feedback effect (closed circle). The right column $(\mathbf{d}-\mathbf{f})$ represents the simulated changes by vegetation feedback effects only. The $y$-axis in right column is same with left column. Dotted line represents LAI changes, and red color in dotted line denotes statistically significant at the $95 \%$ confidence level

suggest that vegetation feedback mainly affects $T_{\max }$. Vegetation feedback through changes in evapotranspiration and albedo occur during daytime (McPherson 2007). The asymmetric effects on $T_{\max }$ and $T_{\min }$ lead to meridional variations in the DTR changes; a decrease in DTR by $0.4^{\circ} \mathrm{K}$ in the mid-latitudes and the increase in DTR by $0.9^{\circ} \mathrm{K}$ in the high-latitudes. Earlier studies also emphasized that the vegetation-temperature relationship is mainly linked to the changes in $T_{\max }$ (e.g., Bonan 2001; Jeong et al. 2009a). Although many previous studies reported the influence of vegetation feedback on shaping temperature changes in a future climate, however, the role of vegetation 
Fig. 7 Schematic diagram for the potential role of the vegetation-climate feedback under doubled $\mathrm{CO}_{2}$ climate in the Northern Hemisphere

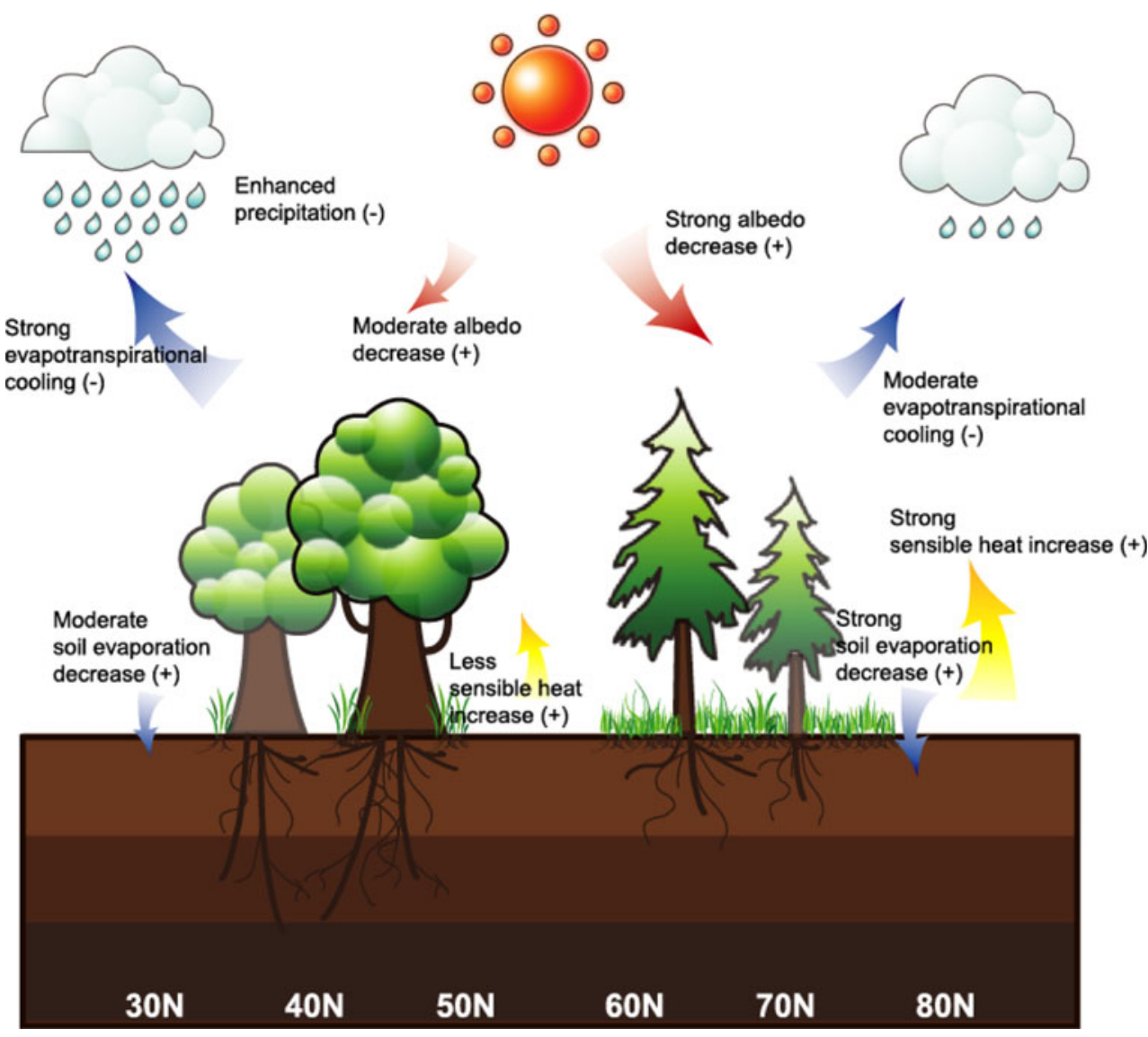

in DTR changes isn't well understood. Thus, our results may improve the understating of future climate change more precisely.

To isolate the vegetation feedback effect only, we didn't use the ocean model in this study. However, the feedback between vegetation and ocean (or sea ice) is also a considerable factor in modulating the temperature changes induced by the $\mathrm{CO}_{2}$ increases, especially in the high-latitudes (Levis et al. 1999; Notaro et al. 2007). Previous studies have reported that vegetation feedback in addition to $\mathrm{CO}_{2}$ increases accelerate sea ice melting in arctic region more rapidly. The role of ocean in atmosphere-ocean-land-vegetation feedback system will be a subject of our follow up studies. Furthermore, biases in simulated vegetation by the CAM3-DGVM may reduce confidence in our findings. In particular, global vegetation is underproductive so that trees are underrepresented while grasses are overrepresented. Nevertheless, our results are largely consistent with previous studies (Betts et al. 1997; Levis et al. 1999; Notaro et al. 2007; Sitch et al. 2008). The CAM3-DGVM simulates only potential natural vegetation and not include the effects of anthropogenic land-use changes (e.g., cropland and urbanization) that can influence climate (Zhao et al. 2001; Matthews et al. 2004; Feddema et al. 2005; Betts et al. 2007). Specifically, Matthews et al. (2004) quantified the relative effects of natural and anthropogenic land cover change. They reported that the net effect of historical anthropogenic land cover change by removing natural vegetation lead to additional warming and moisture depletion. Thus, the effect of land cover change may affect the changes in DTR. But, since the purpose of our model experiments is to evaluate the potential impact of vegetation feedback in the warming, the present results are sufficiently applicable.

\subsection{Conclusions}

Our results show that vegetation plays an active role in shaping the climate system by affecting the energy and water cycle over land surfaces. The increase in the atmospheric $\mathrm{CO}_{2}$ concentrations and the resultant warming increase vegetation greenness, especially in mid- and highlatitude regions. Increased greenness in turn, modulates primarily the changes in the daytime temperature extremes, $T_{\max }$, via altering the surface energy fluxes. Enhanced greenness reduces the warming in mid-latitudes via the vegetation-evapotranspiration feedback, further reinforces the warming via the vegetation-albedo feedback. It is found that dominant feedback mechanisms vary according to latitudes due, in part, to the differences in moisture availability. Our results show that the incorporation of the 
vegetation feedback in climate models is strongly desired for improving the projection of future climate changes.

Acknowledgments This research was funded by the Korea Meteorological Administration Research and Development Program under grant CATER 2006-4204. The authors sincerely appreciate the critical and valuable comments made by two anonymous reviewers.

Open Access This article is distributed under the terms of the Creative Commons Attribution Noncommercial License which permits any noncommercial use, distribution, and reproduction in any medium, provided the original author(s) and source are credited.

\section{References}

Betts RA, Cox PM, Lee SE, Woodward FI (1997) Contrasting physiological and structural vegetation feedbacks in climate change simulations. Nature 387:796-799

Betts RA, Fallon PD, Goldewijk KK, Ramankutty N (2007) Biogeophysical effects of land use on climate: model simulations of radiative forcing and large-scale temperature change. Agric For Meteorol 142:216-233

Bonan GB (2001) Observational evidence for reduction of daily maximum temperature by croplands in the Midwest United States. J Clim 14:2430-2442

Bonan GB (2008) Forest and climate change: forcings, feedbacks, and the climate benefits of forests. Science 320:1444-1449

Bonan GB, Levis S (2006) Evaluating aspects of the Community Land and Atmosphere Models (CLM3 and CAM3) using a dynamic global vegetation model. J Clim 19:2290-2301

Bonan GB, Levis S, Kergoat L, Oleson KW (2002) Landscapes as patches of plant functional types: an integrating concept for climate and ecosystem models. Glob Biogeochem Cycles 16:1021. doi:10.1029/2000GB001360

Bonan GB, Levis S, Sitch S, Vertenstein M, Oleson KW (2003) A dynamical global vegetation model for use with climate models: Concepts and description of simulated vegetation dynamics. Glob Change Biol 9:1543-1566

Bounoua L, Collatz GJ, Sellers PJ et al (1999) Interactions between vegetation and climate: radiative and physiological effects of doubled atmospheric $\mathrm{CO}_{2}$. J Clim 12:309-324

Bounoua L, Collatz GJ, Los SL et al (2000) Sensitivity of climate to changes in NDVI. J Clim 13:2277-2292

Cao L, Bala G, Caldeira K, Nemani R, Ban-Weiss G (2009) Climate response to physiological forcing of carbon dioxide simulated by the coupled community atmosphere model (CAM31) and community land model (CLM30). Geophys Res Lett 36:L10402

Collins WD, Rasch PJ, Boville BA et al (2004) Description of the NCAR Community Atmosphere Model (CAM 3.0). Technical Note NCAR/TN-464+STR, National Center for Atmospheric Research, Boulder, 214 pp

Collins WD, Bitz CM, Blackmon ML et al (2006) The Community Climate System Model Version 3 (CCSM3). J Clim 19:21222243

Cowling SA, Jones PD, Cox PM (2009) Greening the terrestrial biosphere: simulated feedbacks on atmospheric heat and energy circulation. Clim Dyn 32:287-299

Dai A, Trenberth KE, Karl TR (1999) Effects of clouds, soil moisture, precipitation, and water vapor on diurnal temperature range. J Clim 12:2451-2473

Dickinson RE, Oleson KW, Bonan GB et al (2006) The Community Land Model and its climate statistics as a component of the Community Climate System Model. J Clim 19:2302-2324
Easterling DR, Horton B, Jones PD et al (1997) Maximum and minimum temperature trends for the globe. Science 277:364-367

Feddema JJ, Oleson KW, Bonan GB et al (2005) The importance of land-cover change in simulating future climates. Science 310:1674-1678

Fischer EM, Seneviratne SI, Lüthi D, Schär C (2007) Contribution of land-atmosphere coupling to recent European summer heat waves. Geophys Res Lett 34:L06707. doi:10.1029/2006GL02068

Foley JA, Prentice IC, Ramankutty N, Levis S, Pollard D, Sitch S, Haxentine (1996) An integrated biosphere model of land surface processes, terrestrial carbon balance, and vegetation dynamics. Glob Biogeochem Cycles 10(4):603-628

Ho CH, Lee EJ, Lee I, Jeong SJ (2006) Earlier spring in Seoul, Korea. Int J Climatol 26:2117-2127

Jeong SJ, Ho CH, Jeong JH (2009a) Increase in vegetation greenness and decrease in spring time warming over East Asia. Geophys Res Lett 36:L0270. doi:10.1029/2008GL036583

Jeong SJ, Ho CH, Kim KY, Jeong JH (2009b) Reduction of spring warming over East Asia associated with vegetation feedback. Geophys Res Lett 36:L18705. doi:10.1029/2009GL039114

Karl TR, Jones PD, Knight RW et al (1993) A new perspective on recent global warming: asymmetric trends on daily maximum and minimum temperature. Bull Am Meteorol Soc 74:10071023

Kim J, Ek M (1995) A simulation of the long-term surface energy budget and soil water content over the HAPEX-MOBILHY forest site. J Geophys Res 199(D10):20845-20854

Kim J, Kim TK, Arritt RW, Miller N (2002) Impacts of increased atmospheric $\mathrm{CO}_{2}$ on the hydroclimate of the western United States. J Clim 1926-1942

Lawrence DM, Thornton PE, Oleson KW, Bonan GB (2007) The partitioning of evapotranspiration into transpiration, soil evaporation, and canopy evaporation in a GCM: impacts on landatmosphere interaction. J Hydrometeorol 8:862-880

Levis S, Bonan GB (2004) Simulating springtime temperature patterns in the Community Atmosphere Model coupled to the Community Land Model using prognostic leaf area. J Clim $17: 4531-4540$

Levis S, Foley JA, Pollard D (1999) Potential high-latitude vegetation feedbacks on $\mathrm{CO}_{2}$-induced climate change. Geophys Res Lett 26:747-750

Levis S, Foley JA, Pollard D (2000) Large-scale vegetation feedbacks on s doubled $\mathrm{CO}_{2}$ climate. J Clim 13:1313-1325

Levis S, Bonan GB, Vertenstein M, Oleson KW (2004) The Community Land Model's Dynamic Global Vegetation Model (CLM-DGVM): technical description and user's guide. Technical Note NCAR/TN-459+IA, National Center for Atmospheric Research, Boulder, $50 \mathrm{pp}$

Matthews HD, Weaver AJ, Meissner et al (2004) Natural and anthropogenic climate change: incorporating historical land cover change, vegetation dynamics and the global carbon cycle. Clim Dyn 22:461-479

McPherson RA (2007) A review of vegetation-atmosphere interactions and their influences on mesoscale phenomena. Prog Phys Geogr 31(3):261-285

Meehl GA, Stocker TF, Collins WD (2007) Global climate projections. In: Solomon S et al (eds) Climate change 2007: the physical science basis. Contribution of working group 1 to the Fourth Assessment of the Intergovernmental Panel on Climate change. Cambridge University Press, Cambridge, pp 749-844

Myneni RB, Keeling CD, Tucker CJ, Asrar G, Nemani RR (1997) Increased plant growth in the northern high latitudes from 1981 to 1991 . Nature $386: 698-702$

Notaro M, Vavrus S, Liu Z (2007) Global vegetation and climate change due to future increases in $\mathrm{CO}_{2}$ as projected by a fully coupled model with dynamic vegetation. J Clim 20:70-90 
O'ishi R, Abe-Ouchi A (2009) Influence of dynamic vegetation on climate change arising from increasing $\mathrm{CO}_{2}$. Clim Dyn 33(5):645-663

Oleson KW, Dai Y, Bonan GB et al (2004) Technical description of the Community Land Model (CLM). Technical Note NCAR/TN461+STR, National Center for Atmospheric Research, Boulder, $174 \mathrm{pp}$

Schwartz MD, Karl TR (1990) Spring phenology: nature's experiment to detect the effect of 'green-up' on surface maximum temperatures. Mon Weather Rev 118:883-890

Schwartz MD, Ahas R, Aasa A (2006) Onset of spring starting earlier across the Northern Hemisphere. Glob Change Biol 12:343-351

Sitch S, Smith B, Prentice IC et al (2003) Evaluation of ecosystem dynamics, plant geography and terrestrial carbon cycling in the LPJ dynamic global vegetation model. Glob Change Biol 9:161185

Sitch S, Huntingford C, Gedney N et al (2008) Evaluation of terrestrial carbon cycle, future plant geography, and climatecarbon cycle feedback using five Dynamic Global Vegetation Models (DGVMs). Glob Change Biol 14:2015-2039

Solomon S, Qin D, Manning M (2007) Technical summary. In: Solomon S et al (eds) Climate change 2007: The physical science basis. Contribution of working group 1 to the Fourth
Assessment of the Intergovernmental Panel on Climate change. Cambridge University Press, Cambridge, pp 21-87

Stone DA, Weaver AJ (2003) Factors contributing to diurnal temperature range trends in twentieth and twenty-first century simulations of the CCCma coupled model. Clim Dyn 20:435445

Zhang J, Walsh JE (2006) Thermodynamic and hydrological impacts of increasing greenness in northern high latitudes. J Hydrometeorol 7:1147-1163

Zhang J, Wang WC, Wu L (2009) Land-atmosphere coupling and diurnal temperature range over the contiguous United States. Geophys Res Lett 36:L06706. doi:10.1029/2009GL037505

Zhao M, Pitman AJ, Chase T (2001) The impact of land cover change on the atmospheric circulation. Clim Dyn 17:467-477

Zhou L, Dickinson RE, Tian Y, Vose RS, Dai Y (2007) Impact of vegetation removal and soil aridation on diurnal temperature range in a semiarid region: application to Sahel. Proceedings of the National Academy of Sciences of the United States of America, vol 104, pp 17932-17942

Zhou L, Dickinson RE, Dirmeyer P, Dai A, Min SK (2009) Spatiotemporal patterns of changes in maximum and minimum temperatures in multi-model simulations. Geophys Res Lett 36:L02702. doi:10.1029/2008GL03641 